\section{Freier Verband Deutscher Zahnärzte e.V.}

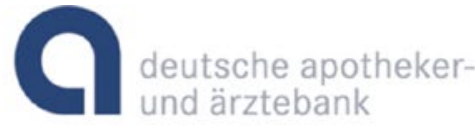

\title{
ETL Akademie
} villa Westerberge

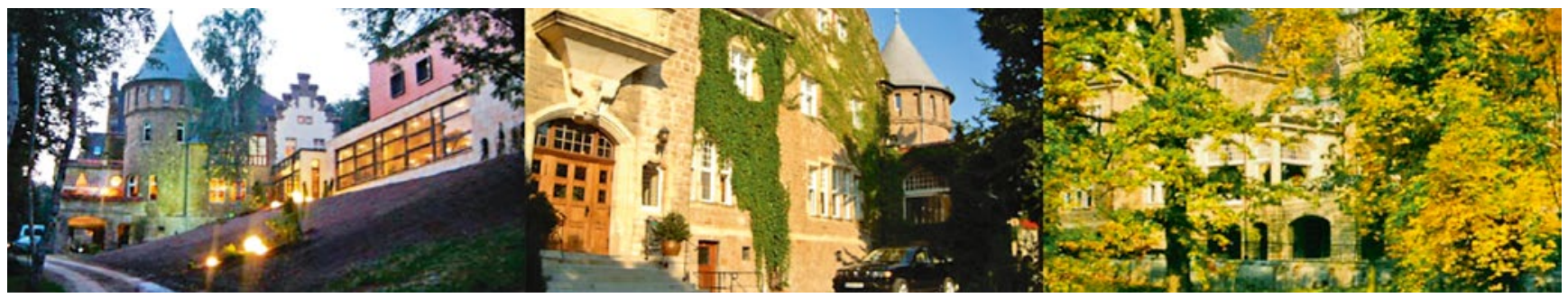

\section{Einladung Landesversammlung Sachsen-Anhalt: „Tagen und genießen“}

Sehr verehrte Frau Kollegin, sehr geehrter Herr Kollege,

der FVDZ Sachsen-Anhalt lädt Sie herzlich zur Landesversammlung 2016 in außergewöhnlicher Atmosphäre in die ETL Akademie Villa Westerberge nach Aschersleben ein.

Beginn: Freitag, 22. April 2016 von 15.30 Uhr bis etwa 19.00 Uhr, Akademie Villa Westerberge, An den Westerbergen 1, 06449 Aschersleben

Begrüßung: Matthias Tamm - Landesvorsitzender FVDZ Landesverband Sachsen-Anhalt

1. Teil: Aktuelle steuerliche Themen der Zahnarztpraxis, Neuigkeiten aus Betriebsprüfungen.

Personalkostenentwicklung in der Zahnarztpraxis nach Einführung Mindestlohn, aktuelle betriebswirtschaftliche Vergleichszahlen für Zahnarztpraxen.

ETL | ADMEDIO GmbH Steuerberatungsgesellschaft Referenten: Christiane Müller, Steuerberaterin Andreas Mauder, Steuerberater, Dipl.-Kaufmann (FH), Fachberater für den Heilberufebereich (IFU/ISM gGmbH)

- Bericht des Landesvorsitzenden

- Anträge und Beschlussfassung

- Bericht der Kassenprüfer, Entlastung des Vorstands

- Haushaltsplan 2016

Ende der Versammlung - 1. Teil

etwa 19.00 Uhr - anschließend ein gemeinsames Abendessen

Fortsetzung: Samstag, 23. April 2016 von 9.30 Uhr bis etwa 12.30 Uhr, Akademie Villa Westerberge, An den Westerbergen 1, 06449 Aschersleben

Factoring für Zahnärzte mit der BFS Service $\mathrm{GmbH}$, Henrik Meye
Die Praxisbörse der Apotheker- und Ärztebank - Vermittlungsservice für Abgeber.

Referent: Ingo König - Filialdirektor, Deutsche Apotheker- und Ärztebank Magdeburg

2. Teil: Aktuelle steuerliche Themen der Zahnarztpraxis, Neuigkeiten aus Betriebsprüfungen.

Personalkostenentwicklung in der Zahnarztpraxis nach Einführung Mindestlohn, aktuelle betriebswirtschaftliche Vergleichszahlen für Zahnarztpraxen.

ETL | ADMEDIO GmbH Steuerberatungsgesellschaft Referenten: Christiane Müller, Steuerberaterin Andreas Mauder, Steuerberater, Dipl.-Kaufmann (FH), Fachberater für den Heilberufebereich IFU/ISM gGmbH

Für diese Veranstaltung werden 7 Fortbildungspunkte vergeben.

Der Landesvorstand lädt hiermit gemäß $₫ 14$ Abs. 2-6 der Satzung seine stimmberechtigten Mitglieder zur Landesversammlung ein. Anträge und Beschlussvorlagen sind spätestens zwei Wochen vor der Landesversammlung über die Geschäftsstelle schriftlich einzureichen und zu begründen.

Für die Teilnehmer besteht die Möglichkeit, eine Übernachtung auf eigene Kosten zu buchen.

Bitte senden Sie uns für Ihre Anmeldung und sofern Sie in der Villa Westerberge übernachten möchten, möglichst bis zum 15. April 2016, das beiliegende Antwortfax ausgefüllt zurück. Da die Übernachtungsmöglichkeiten begrenzt sind, werden die Anmeldungen in der Reihenfolge des Eingangs berücksichtigt.

Mit freundlichen Grüßen

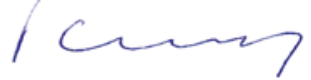

Matthias Tamm, Landesvorsitzender 